\title{
Highly Conducting Lyotropic Liquid Crystalline Mesophases of Pluronics (P65, P85, P103, and P123) and Hydrated Lithium Salts (LiCl and $\mathrm{LiNO}_{3}$ )
}

\author{
Gözde Barım, Cemal Albayrak, Ezgi Yılmaz, and Ömer Dag* \\ Department of Chemistry, Bilkent University, 06800 Ankara, Turkey \\ Supporting Information
}

\begin{abstract}
Demand for ionically conducting materials, as membranes and electrodes, is one of the driving forces of current research in chemistry, physics, and engineering. The lithium ion is a key element of these materials, and its assembly into nanostructures and mesophases is important for the membrane and electrode technologies. In this investigation, we show that hydrated lithium salts (such as $\mathrm{LiCl} \cdot x \mathrm{H}_{2} \mathrm{O}$ and $\mathrm{LiNO}_{3}$. $x \mathrm{H}_{2} \mathrm{O}, x$ is as low as 1.5 and 3.0, respectively) and pluronics (triblock copolymer such as $\mathrm{PX}$ where $X$ is $65,85,103$, and 123) form lyotropic liquid crystalline mesophases (LLCM), denoted as $\mathrm{LiY} \cdot x \mathrm{H}_{2} \mathrm{O}-\mathrm{PX}-n\left(\mathrm{Y}\right.$ is $\mathrm{Cl}^{-}$or $\mathrm{NO}_{3}^{-}$, and $n$ is the salt/PX mole ratio). The

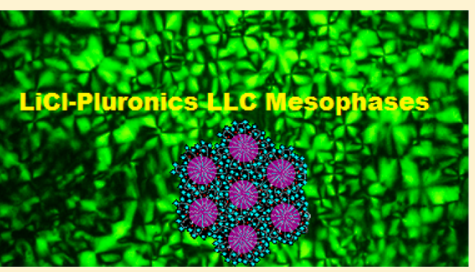
structure of the mesophase is hexagonal over a broad salt concentration and transforms to a cubic mesophase and then to disordered gel phase with an increasing salt content of the mixtures. The mesophases are unstable at low salt contents and undergo a phase separation into pure pluronics and salt-rich LLCMs. The salt content of the ordered mesophase can be as high as 30 mole ratio for each pluronic, which is a record high for any known salted phases. The mesophases also display high ac ionic conductivities, reaching up to $21 \mathrm{mS} / \mathrm{cm}$ at room temperature (RT), and are sensitive to the water content. These mesophases can be useful as ion-conducting membranes and can be used as media for the synthesis of lithium-containing nanoporous materials.
\end{abstract}

\section{INTRODUCTION}

Nanostructured materials are important for the development of new advanced technologies, specifically, for clean energy. ${ }^{1-4}$ However, nanoscale materials need to be designed or assembled (preferentially self-assembled) into the next scale (micrometer or larger) for practical applications. One approach to achieve this assembly is known as a lyotropic liquid crystalline (LLC) templating approach, where the surfactants or block copolymers are used as directing agents. ${ }^{5-9}$ The LLC mesophase is a self-assembly process and consists of solvent and surfactant molecules. The phase behavior of oligo(ethylene oxide) $\left(\mathrm{C}_{n} \mathrm{H}_{2 n+1}\left(\mathrm{OCH}_{2} \mathrm{CH}_{2}\right)_{m} \mathrm{OH}\right.$ represented as $\left.\mathrm{C}_{n} \mathrm{EO}_{m}\right)$ type nonionic surfactants and pluronics has been extensively investigated using various solvents such as water, ${ }^{10-13}$ salt solutions, ${ }^{14-16}$ room temperature ionic liquids, ${ }^{17}$ supercritical carbon dioxiode, ${ }^{18}$ some organic sovents, ${ }^{19}$ oil-water mixtures, ${ }^{20,21}$ and some salts (salt-surfactant mesophases). ${ }^{22}$ The salt-surfactant LLC mesophases have been known since $2001 .^{22}$ The metal salts act as a solvent in the salt-surfactant mesophase, ${ }^{23}$ which can be beneficial for the synthesis of porous metal oxide materials for clean energy applications. ${ }^{24}$ There are three important parameters (for a stable saltsurfactant mesophase and salt as a good solvent) for this assembly process, namely a low melting point, low deliquescent relative humidity (DRH), and a counteranion of the salt. ${ }^{23-25}$

Lithium ion technologies are very important in clean energy applications, particularly in rechargeable batteries. ${ }^{26,27}$ Assembling lithium ions into LLC mesophase can be beneficial for these technologies as lithium ion gel electrolytes ${ }^{28-33}$ and media for the synthesis of mesostructured lithium metal oxides as anode and cathode materials. ${ }^{34-40}$ Moreover, these electrolytes and electrodes can be used for the development of the other technologies, such as solar cells, ${ }^{41}$ fuel cells, ${ }^{42}$ electrochromic devices, ${ }^{43}$ etc. Most lithium salts (such as $\mathrm{LiCl}, \mathrm{LiBr}$, LiI, $\mathrm{LiClO}_{4}$, and $\mathrm{LiNO}_{3}$ ) are known to form LLC mesophases with nonionic surfactants, such as 10-lauryl ether $\left(\mathrm{C}_{12} \mathrm{H}_{25}\left(\mathrm{OCH}_{2} \mathrm{CH}_{2}\right)_{10} \mathrm{OH}, \mathrm{C}_{12} \mathrm{EO}_{10}\right)$ and 10-octadecyl ether $\left(\mathrm{C}_{18} \mathrm{H}_{37}\left(\mathrm{OCH}_{2} \mathrm{CH}_{2}\right)_{10} \mathrm{OH}, \mathrm{C}_{18} \mathrm{EO}_{10}\right) .{ }^{43}$ The salt-surfactant LLC mesophases exist because of the soft confinement effect (SCE). The SCE reduces the melting point (such as the melting point of zinc nitrate hexahydrate drops down to -52 ${ }^{\circ} \mathrm{C}$ in the LLC phase of this salt and $\left.\mathrm{C}_{12} \mathrm{EO}_{10}\right)^{23}$ and also enhances the solubility of salts ${ }^{43}$ in the hydrophilic domains of the LLC mesophases and as a result causes salt and highly concentrated salt solutions to act as a solvent in the saltsurfactant LLC mesophases.

The salt-pluronic mesophases (SPM) have been briefly investigated for some transition metal salts. ${ }^{44}$ Pluronics are triblock copolymers (two poly(ethylene oxide)s on each end of a poly(propylene oxide) block in the middle, $\mathrm{H}\left(\mathrm{OCH}_{2} \mathrm{CH}_{2}\right)_{n}$ $\left(\mathrm{OCHCH}_{3} \mathrm{CH}_{2}\right)_{m}\left(\mathrm{OCH}_{2} \mathrm{CH}_{2}\right)_{n} \mathrm{OH}$, represented as $\mathrm{PX}$, where $X$ is a number related to molecular weight and percent ethylene oxide unit). The SPMs have rich mesostructures that include lamella, hexagonal, tetragonal, and cubic phases. ${ }^{44}$ In this

Received: February 14, 2014

Revised: $\quad$ May 9, 2014

Published: May 29, 2014 
investigation, two different lithium salts (namely $\mathrm{LiCl}$ and $\mathrm{LiNO}_{3}$ ) and four pluronics (P65, P85, P103, and P123) were investigated in their LLC mesophases using PXRD, POM, FTIR, Raman, and ac impedance conductivity measurements. Notice that these surfactants have been chosen from large group of pluronics and have $50 \%$ and $30 \%$ ethylene oxide units with a low and high molecular weight. Therefore, the effect of ethylene oxide units on the mesophases has been investigated. The lithium-containing LLC mesophases can be useful as a lithium ion gel membrane and as a reaction media for the synthesis of large pore mesoporous lithium metal oxides, which are also important in the development of lithium ion batteries. Toward these goals, the LLC mesophases of the lithium salts with pluronics need to be explored.

\section{EXPERIMENTAL PART}

Preparation of the Samples. Samples were prepared as gels and solutions with the compositions given in Table 1. The solution

Table 1. Phase Behavior of the $\mathrm{LiCl} \cdot x \mathrm{H}_{2} \mathrm{O}-\mathrm{PX}-n$ Systems at RT and 22-25\% RH (H = Normal Hexagonal Phase, $\mathrm{I}=$ Micelle Cubic Phase)

\begin{tabular}{lcccccccc} 
& \multicolumn{8}{c}{ salt/pluronic mole ratio } \\
\cline { 2 - 9 } salt-pluronic & 5.0 & 6.0 & 8.0 & 10.0 & 12.0 & 15.0 & 20.0 & 25.0 \\
$\mathrm{LiCl}-\mathrm{P} 65$ & & $\mathrm{H}$ & $\mathrm{H}$ & $\mathrm{H}$ & $\mathrm{H}$ & $\mathrm{H}$ & $\mathrm{I}$ & \\
$\mathrm{LiCl}-\mathrm{P} 85$ & & & $\mathrm{H}$ & $\mathrm{H}$ & $\mathrm{H}$ & $\mathrm{H}$ & $\mathrm{I}$ & \\
$\mathrm{LiCl}-\mathrm{P} 103$ & $\mathrm{H}$ & $\mathrm{H}$ & $\mathrm{H}$ & $\mathrm{H}$ & $\mathrm{H}$ & $\mathrm{I}$ & & \\
$\mathrm{LiCl}-\mathrm{P} 123$ & & $\mathrm{H}$ & $\mathrm{H}$ & $\mathrm{H}$ & $\mathrm{H}+\mathrm{I}$ & $\mathrm{H}+\mathrm{I}$ & $\mathrm{I}$ & $\mathrm{I}$ \\
$\mathrm{LiNO}_{3}-\mathrm{P} 103$ & & $\mathrm{H}$ & $\mathrm{H}$ & $\mathrm{H}$ & $\mathrm{I}$ & $\mathrm{I}$ & $\mathrm{I}$ & \\
$\mathrm{LiNO}_{3}-\mathrm{P} 123$ & & $\mathrm{H}$ & $\mathrm{H}$ & $\mathrm{H}$ & $\mathrm{H}$ & $\mathrm{I}$ & $\mathrm{I}$ & $\mathrm{I}$ \\
\hline
\end{tabular}

samples are easy to prepare and are spin-coated over a substrate which allows quick evaporation of the excess water and leaves behind an LLC mesophase of the corresponding salt and pluronic. In a typical preparation of a solution, $0.125 \mathrm{~g}$ of $\mathrm{LiCl}$ (or $0.203 \mathrm{~g}$ of $\mathrm{LiNO}_{3}$ ) was dissolved in $5 \mathrm{~mL}$ of water, and then $1.0 \mathrm{~g}$ of $\mathrm{P} 65$ was added and the solution was stirred for $60 \mathrm{~min}$ to ensure homogenization and labeled as $\mathrm{LiCl}\left(\right.$ or $\mathrm{LiNO}_{3}$ ) $x \mathrm{H}_{2} \mathrm{O}-\mathrm{P} 65-10$ (where 10 is the salt/P65 mole ratio). All other compositions were prepared by only changing the amount of the salt to vary the salt/pluronic mole ratio between 1 and 30 and were labeled as $\mathrm{LiCl}\left(\right.$ or $\left.\mathrm{LiNO}_{3}\right) \cdot x \mathrm{H}_{2} \mathrm{O}-\mathrm{PX}-n(X$ is $65,85,103$, and 123 with average molecular weights of 3400,4600 , 4950, and 5750 $\mathrm{g} / \mathrm{mol}$, respectively, and $n$ is the salt/PX mole ratio). The gel phases were prepared like solution phases, except the amount of water was kept as little as $1.5-3$ waters per lithium salt, and the homogenization was carried out over 2 days in a shaking bath at $80^{\circ} \mathrm{C}$. The contents of the samples after spin-coating of the solution and after spreading of the gel phases are more or less the same.

Instrumentation. The X-ray diffraction (XRD) patterns were recorded on a Rigaku Miniflex diffractometer using a high-power $\mathrm{Cu}$ $\mathrm{K} \alpha$ source operating at $30 \mathrm{kV} / 15 \mathrm{~mA}$ and a wavelength of $1.5405 \AA$. The measurements were carried out by spreading the samples on glass slides by spin-coating. The measurements were done at various scan rates (ranging from 0.1 to $1 \theta / \mathrm{min}$ ) at 0.01 data intervals. The polarized optical microscopy (POM) images were obtained in transmittance mode by using a ZEISS Axio Scope.A1 polarizing optical microscope with a Linkam LTS350 temperature controlling stage attached to the microscope. The temperature control was performed by using a LinkamT95-LinkPad temperature programmer attached to the stage. The Fourier transform infrared (FTIR) spectra were recorded using a Bruker Tensor 27 model FTIR spectrometer. A Digi Tect TM DLATGS detector was used with a resolution of 4.0 $\mathrm{cm}^{-1}$ in the $400-4000 \mathrm{~cm}^{-1}$ range. The spectra were recorded by either spreading the samples on silicon wafers or sandwiching them between two silicon wafers in order to prevent the evaporation of water. The FTIR spectra of the samples were collected using 128 scans. The micro-Raman spectra were recorded on a LabRam confocal Raman microscope with a $300 \mathrm{~mm}$ focal length. The spectrometer was equipped with a Ventus LP 532, $50 \mathrm{~mW}$, diode pumped solid-state laser operator at $20 \mathrm{~mW}$, with a polarization ratio of $100: 1$, a wavelength of $532.1 \mathrm{~nm}$, and a $1024 \times 256$ element CCD camera. The signal collected was transmitted via a fiber-optic cable into a spectrometer with 600 grooves $/ \mathrm{mm}$ grating. The Raman spectra were collected by manually placing the probe tip on the desired point of the sample over the glass or silicon wafer. The ac impedance conductivity measurements were performed using a Gamry G750 potentiostat/galvanostat with a homemade conductivity cell equipped with two stainless-steel electrodes. The cell constant for the conductivity cell was determined by using a standard solution of $\mathrm{KCl}$ at room temperature (RT). The measurements at $\mathrm{RT}$ were performed by immersing the conductivity cell in a water bath.
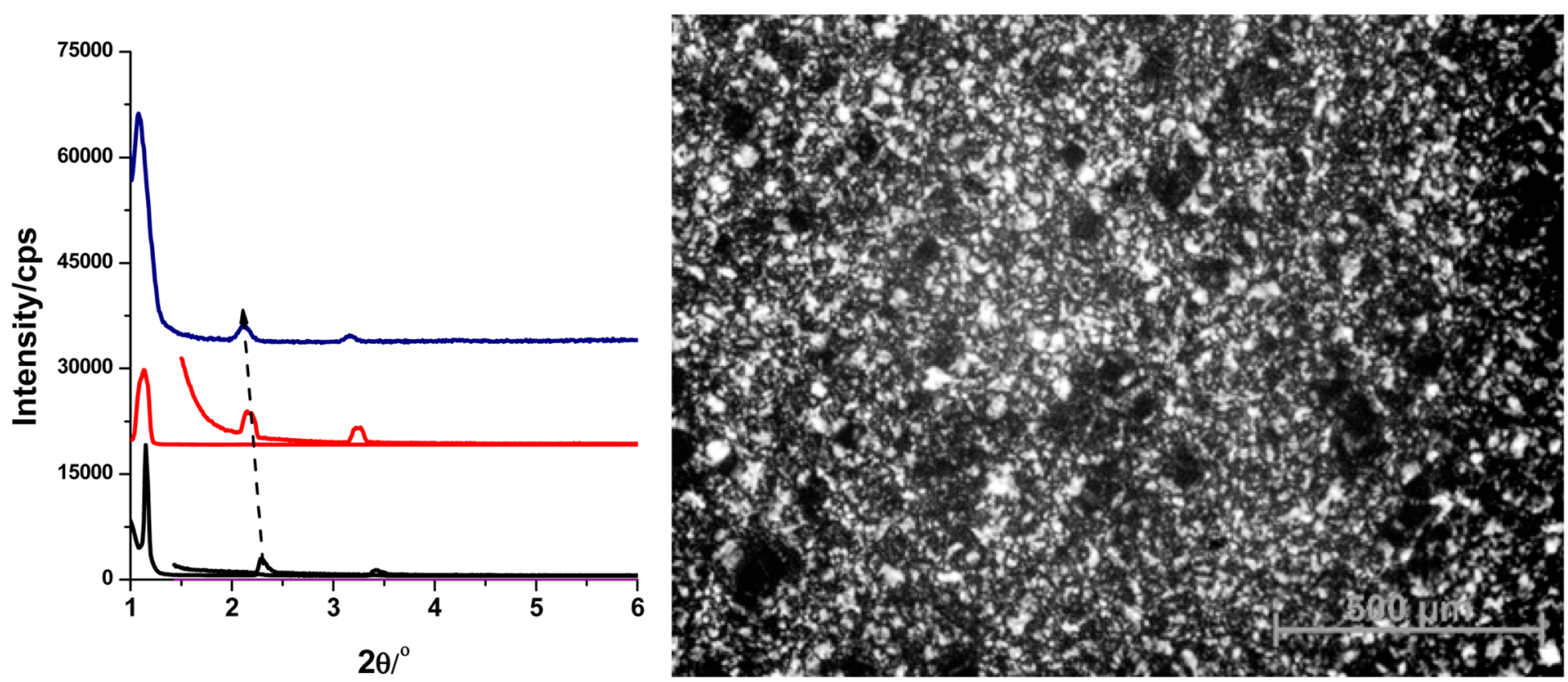

Figure 1. Small-angle $\mathrm{XRD}$ patterns of the $\mathrm{LiCl} \cdot x \mathrm{H}_{2} \mathrm{O}-\mathrm{P} 65-n$ mesophases, where $n$ is 8.0, 12.0, and 15.0 (from bottom to top on the left), and a POM image of $\mathrm{LiCl} \cdot x \mathrm{H}_{2} \mathrm{O}-\mathrm{P} 65-10$ (right). 
Resistance data were recorded for all conductivity measurements after the equilibration of the sample temperature in the bath temperature.

\section{RESULTS AND DISCUSSION}

Lyotropic Liquid Crystalline Mesophases of Pluronics (P65, P85, P103, and P123) with $\mathrm{LiCl}$ and $\mathrm{LiNO}_{3}$ Salts. $\mathrm{A}$ mixture of $\mathrm{LiCl}\left(\right.$ or $\left.\mathrm{LiNO}_{3}\right)$ salt and $\mathrm{P} 65\left(\mathrm{EO}_{20} \mathrm{PO}_{30} \mathrm{EO}_{20}\right)$ (or P85 $\left(\mathrm{EO}_{26} \mathrm{PO}_{40} \mathrm{EO}_{26}\right)$, or P103 $\left(\mathrm{EO}_{17} \mathrm{PO}_{55} \mathrm{EO}_{17}\right)$, or P123 $\left.\left(\mathrm{EO}_{20} \mathrm{PO}_{70} \mathrm{EO}_{20}\right)\right)$ triblock copolymers form stable lyotropic liquid crystalline (LLC) mesophases over a broad range of salt concentrations in the presence of as low as 1.5 water molecules per salt. The LLC mesophases of the $\mathrm{LiCl}$ salt were labeled as $\mathrm{LiCl} \cdot x \mathrm{H}_{2} \mathrm{O}-\mathrm{P} 65-n, \mathrm{LiCl} \cdot x \mathrm{H}_{2} \mathrm{O}-\mathrm{P} 85-n, \mathrm{LiCl} \cdot x \mathrm{H}_{2} \mathrm{O}-\mathrm{P} 103-n$, and $\mathrm{LiCl} \cdot x \mathrm{H}_{2} \mathrm{O}-\mathrm{P} 23-n$, where $n$ is between 6.0 and 25.0 (15 and 42 wt \%), 10.0 and 25.0 (12 and 34 wt \%), 6.0 and 20.0 (10 and 28 wt \%), and 8.0 and 25.0 (12 and $30 \mathrm{wt} \%) \mathrm{LiCl} /$ pluronic mole ratios, respectively (see Table 1). All the samples with a low salt content have leached out some surfactant crystals, due to insufficient amount of salt to organize surfactant molecules into mesophases. However, at very high salt concentrations (above 30 salt/pluronic mole ratio) the systems leached out the salt crystals slowly over time. The fresh samples with an intermediate composition form homogeneous and stable mesophases (salt or pluronic crystals were not observed over 6 months by means of PXRD, microscopy and spectroscopy). The structure of the LiY. $x \mathrm{H}_{2} \mathrm{O}-\mathrm{PX}-n$ ( where $\mathrm{Y}$ is $\mathrm{Cl}^{-}$or $\mathrm{NO}_{3}^{-}$) mesophases were identified using PXRD patterns and POM images of the samples that were either spin-coated over a glass surface or drop-casted from a homogenized $\mathrm{LiCl}\left(\right.$ or $\mathrm{LiNO}_{3}$ ), water, and pluronic solution. Table 1 also summarizes the phase behavior of the samples of various pluronics (P65, P85, P103, and $\mathrm{P} 123)$ and hydrated lithium salts $\left(\mathrm{LiCl}\right.$ and $\left.\mathrm{LiNO}_{3}\right)$.

The $\mathrm{LiCl} \cdot x \mathrm{H}_{2} \mathrm{O}-\mathrm{P} 65-n$ samples, with a broad range of $\mathrm{LiCl}$ concentrations, display small-angle diffraction lines in the $2 \theta$ range of $1.0^{\circ}-5.0^{\circ}$. Figure 1 shows the XRD patterns of the $\mathrm{LiCl} \cdot x \mathrm{H}_{2} \mathrm{O}-\mathrm{P} 65-n$ (where $n$ is 8,12 , and 15 ) samples and a representative POM image under ambient conditions. The diffraction patterns are characteristic for the $2 \mathrm{D}$ hexagonal LLC mesophase with a unit cell parameter $a$ of $87.1 \AA$. The hexagonal LLC mesophase is observed between 6 and $15 \mathrm{LiCl} /$ P65 mole ratios. The unit cell parameter increases with an increasing salt concentration, and it was calculated as $96.7 \AA$ for $n=15$. The cubic mesophase exists above 15 and extends up to a $25 \mathrm{LiCl} / \mathrm{P} 65$ mole ratio. Above a 25 mole ratio, the mixture is still gel-like but does not diffract at small angles (see Figure S1), indicating a disordered mesophase.

Figure 2 and Figure S2 display the PXRD patterns of the LLC mesophases of the $\mathrm{LiCl} \cdot x \mathrm{H}_{2} \mathrm{O}-\mathrm{P} 85-n$ at different salt to surfactant mole ratios. The first diffraction line corresponds to the (002) plane and the others to (200), (201), (204), (301), (313), and (324) planes of the 3D hexagonal mesophase and provides a unit cell parameter $a$ of $108.8 \AA, c$ of $177.2 \AA$, and $c /$ $a$ of 1.629 in the $\mathrm{LiCl} \cdot x \mathrm{H}_{2} \mathrm{O}-\mathrm{P} 85-12$ sample (see Figure 2). The hexagonal mesophase was observed between 8.0 and $15.0 \mathrm{LiCl} /$ P85 mole ratios in the $\mathrm{LiCl} \cdot x \mathrm{H}_{2} \mathrm{O}-\mathrm{P} 85-n$. Under a salt to surfactant mole ratio of 8.0, some surfactant molecules crystallized and were leached out from the mixture. However, the characteristic fan texture of the LLC hexagonal mesophase was observed under the surfactant crystals (see Figure S3). This indicates that the salt concentration was not enough to organize the surfactant molecules into an LLC mesophase below 8.0 $\mathrm{LiCl} / \mathrm{P} 85$ mole ratios. The mixtures undergo a phase separation into salt-free (pure surfactant) and salt-rich (LLC) domains at

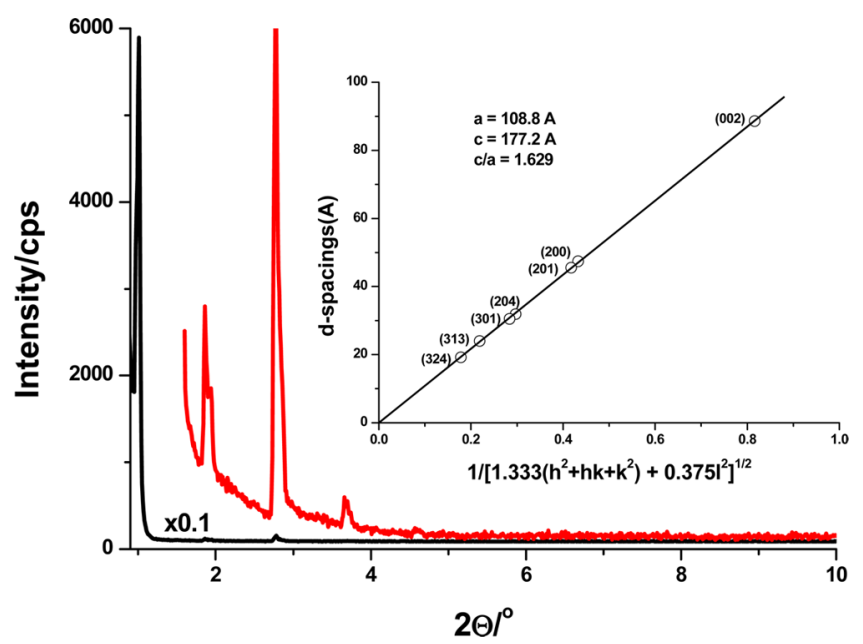

Figure 2. $\mathrm{XRD}$ patterns, at small angles, of $\mathrm{LiCl} \cdot x \mathrm{H}_{2} \mathrm{O}-\mathrm{P} 85-n$, where $n$ is 12.0 mole ratios (inset is the plot of $d$-spacing versus $h k l$ relationship for hexagonal phase).

low salt concentrations, demonstrating that the mesophase is one of the stable phases of the salt-surfactant mixtures.

The LLC mesophase of the $\mathrm{LiCl} \cdot x \mathrm{H}_{2} \mathrm{O}-\mathrm{P} 103-n$ samples is also birefringent over a broad range of salt concentrations, under the polarized optical microscope, indicating the presence of the hexagonal mesophase (see Figure 3). The PXRD data and POM images collectively provide insights into the structure of the mesophases. The first diffraction line is most likely below $1.0^{\circ}$ of $2 \theta$; therefore, it could not be detected by our diffractometer in its current setup. ${ }^{45}$ Notice that P103 is a much larger molecules compared to both P65 and P85 and forms much larger unit cells; therefore, the first diffraction line must be at smaller angles. ${ }^{45}$ The POM images of these samples display fanlike textures under ambient conditions, also indicating the presence of the hexagonal LLC mesophase (see Figure 3). Therefore, the POM images and PXRD patterns were collectively used to identify the structure of the $\mathrm{LiCl}$. $x \mathrm{H}_{2} \mathrm{O}-\mathrm{P} 103-n$ samples, and the data show the presence of hexagonal mesophase between the 6 and 12 salt to surfactant mole ratios. At higher salt concentrations, the mesophase is usually cubic and displays no texture under the POM. Figure S4 displays the diffraction pattern of all the $\mathrm{LiCl} \cdot x \mathrm{H}_{2} \mathrm{O}-\mathrm{P} 103-n$ samples. For example, the sample where $n$ is 15 displays five diffraction lines that could be indexed to (100), (200), (300), (400), and (500) with a unit cell parameter $a$ of about $128.7 \AA$. Even though the phase is hexagonal, one observes only planes along the same direction, indicating that the mesophase is quite oriented. The POM images of the $\mathrm{LiCl} \cdot \mathrm{H}_{2} \mathrm{O}-\mathrm{P} 103-15$ sample have no texture and are completely dark between the crossed polarizers, which confirms the presence of a cubic mesophase. The diffraction lines disappears at around $20.0 \mathrm{LiCl} / \mathrm{P} 103$ mole ratio; the ordered LLC mesophase was not observed at higher salt concentrations, although the samples were still gel-like (see Figure S4). Notice also that the surfactant separation in the $\mathrm{LiCl} \cdot x \mathrm{H}_{2} \mathrm{O}-\mathrm{P} 103-n$ mesophases occurs at lower salt concentrations. The origin of the surfactant separation, at low salt concentrations, can be attributed to the percent $\mathrm{EO}$ units of the pluronics. Notice that both P65 and P85 have about 50\% ethylene oxide blocks compared to $30 \%$ in P103 and P123. Therefore, the surfactants with more EO units (such as in P65 and P85) require more salts to minimize the surfactant- 

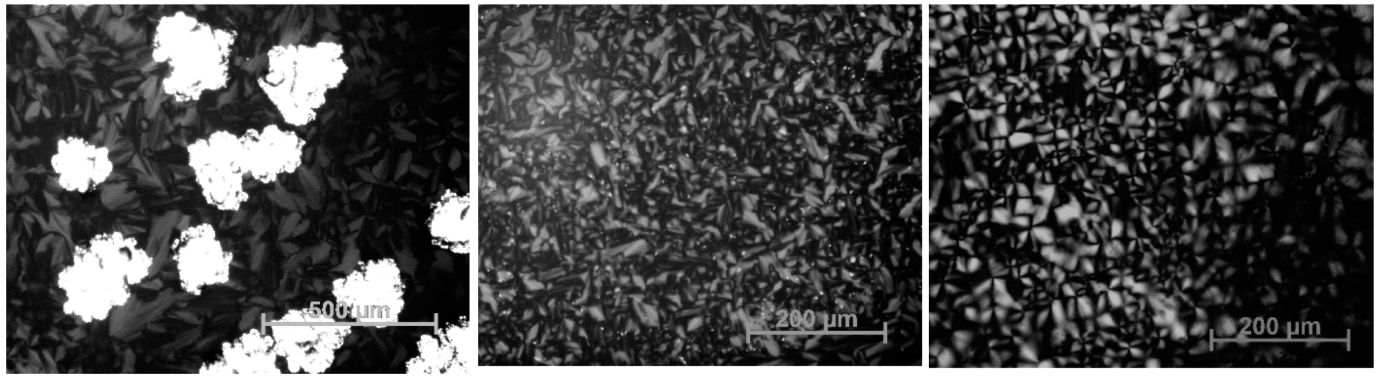

Figure 3. POM images of (left) $\mathrm{LiCl} \cdot \mathrm{xH}_{2} \mathrm{O}-\mathrm{P} 103-3$, (middle) $\mathrm{LiCl} \cdot x \mathrm{H}_{2} \mathrm{O}-\mathrm{P} 103-6$, and (right) $\mathrm{LiCl} \cdot x \mathrm{H}_{2} \mathrm{O}-\mathrm{P} 123-6$ hexagonal mesophase.

surfactant repulsive interactions through the EO blocks which lead the phase separation.

The PXRD patterns of the $\mathrm{LiCl} \cdot x \mathrm{H}_{2} \mathrm{O}-\mathrm{P} 123-n$ samples, where $n$ is between 6 and 30, also display diffraction lines at small angles. The samples are birefringent and display a fan texture under the polarized optical microscope over a broad range of salt concentrations, indicating the presence of the hexagonal mesophase (Figure 3 ). The small-angle diffractions correspond to (200), (300), and (400) and provide a unit cell parameter $a$ of $134.3 \AA$. At higher salt concentrations, the diffraction lines shift to higher angles, and the POM texture disappears like in the other pluronic systems. This means that there is a phase change at around the 15 salts to surfactant mole ratio (see Figure S5). The sample with a $30 \mathrm{LiCl} / \mathrm{P} 123$ mole ratio and above does not diffract at small angles. Hence, there is either no LLC mesophase at higher salt concentrations or the phase is completely disordered (which has not been further investigated). In all $\mathrm{LiCl} \cdot x \mathrm{H}_{2} \mathrm{O}$-pluronics, the mesophases are hexagonal in the intermediate and undergo phase changes from a hexagonal to cubic mesophases and from a cubic to a disordered phases with increasing $\mathrm{LiCl}$ mole ratios. The $\mathrm{LiCl} /$ pluronic mole ratio can be increased up to 30. The mesophase at low salt concentrations leaches out the excess surfactants. The mesophases are stable for months under ambient conditions in the intermediate salt/surfactant mole ratios.

To extend the salt-pluronic systems, we also investigated the $\mathrm{LiNO}_{3} \cdot x \mathrm{H}_{2} \mathrm{O}-\mathrm{P} 103-n$ and $\mathrm{LiNO}_{3} \cdot x \mathrm{H}_{2} \mathrm{O}-\mathrm{P} 123-n$ samples using the PXRD and POM techniques. The $\mathrm{LiNO}_{3} \cdot x \mathrm{H}_{2} \mathrm{O}-\mathrm{P} 103-n$ samples display small-angle diffraction lines, where the first line is observed at around $2.0^{\circ} 2 \theta$. The intensity of the first diffraction line decreases and shifts to lower angles with an increasing salt concentration (see Figure S6). The diffraction patterns of the spin-coated samples have three different diffraction lines that can be indexed to the (200), (300), and (400) planes of the hexagonal mesophase, indicating an orientation along the [100] direction. The samples between 8 and 15 salt to surfactant mole ratios have a hexagonal mesophase with a cell parameter $a$ of about $104.4 \AA$ (see Figure S6). It is also important to note that the POM images display a characteristic fanlike texture between 6 and 15 in the $\mathrm{LiNO}_{3} \cdot x \mathrm{H}_{2} \mathrm{O}-\mathrm{P} 103-n$ samples. Figure $\mathrm{S} 7$ displays the diffraction pattern of the $\mathrm{LiNO}_{3} \cdot x \mathrm{H}_{2} \mathrm{O}-\mathrm{P} 123-n$ samples under ambient conditions. The diffraction pattern is characteristic of a $2 \mathrm{D}$ hexagonal LLC mesophase with a unit cell parameter $a$ of about 121.2 A. The patterns have three diffraction lines that can be indexed to the (100), (200), and (300) planes of the hexagonal mesophase. The diffraction lines gradually shift to lower angles up to a 15 mole ratio, where the hexagonal to cubic mesophase change occurs (see Figure S7), and then shift to higher angles, starting from the $15 \mathrm{LiNO}_{3} / \mathrm{P} 123$ mole ratios, and the characteristic fan texture of the hexagonal LLC mesophase disappears at high salt concentrations. The phase transition from the hexagonal to cubic LLC mesophase occurs at around a 15 salt to surfactant mole ratio. The LLC mesophase of the $\mathrm{LiNO}_{3} \cdot x \mathrm{H}_{2} \mathrm{O}-\mathrm{P} 123-n$ is stable and ordered up to $n=25$.

According to the PXRD and POM data, the $\mathrm{LiCl} \cdot x \mathrm{H}_{2} \mathrm{O}$ pluronic samples display hexagonal mesophases over a broader range of salt concentrations than the $\mathrm{LiNO}_{3} \cdot x \mathrm{H}_{2} \mathrm{O}$-pluronic systems. Moreover, the hexagonal to cubic phase transition occurs at lower salt concentration in the $\mathrm{LiNO}_{3} \cdot x \mathrm{H}_{2} \mathrm{O}$ pluronics systems. Also notice that the unit cell of the $\mathrm{LiNO}_{3} \cdot x \mathrm{H}_{2} \mathrm{O}-\mathrm{P} 103-n$ is about $15-20 \%$ smaller compared to the $\mathrm{LiCl} \cdot \mathrm{x}_{2} \mathrm{O}-\mathrm{P} 103-n$, and it is $10 \%$ smaller in the $\mathrm{P} 123$ systems. All these trends are related to the Hofmeister series in that the $\mathrm{NO}_{3}{ }^{-}$ion has a more water structure breaking nature than that of the $\mathrm{Cl}^{-}$ion. Therefore, chloride ions make the pluronics less hydrated with water molecules and enhance the interfacial curvature of the pluronics. Simply, the nitrate ions carry water to the vicinity of hydrophilic-hydrophobic interface region in the LLC mesophase. Similarly, the nitrate ions enhance the hydration of the hydrophilic ethylene oxide units, and the interfacial curvature increases again and results in smaller unit cells. The increase in the concentration of water structure breaking ions leads to an increase in the repulsive forces between the hydrophilic units. As a result, the hexagonal mesophase exists over a narrower range of salt concentrations in the $\mathrm{LiNO}_{3} \cdot x \mathrm{H}_{2} \mathrm{O}$-pluronic mesophases. To elucidate the details of these interactions, we also measured the FTIR and Raman spectra of all the samples with different water contents.

Hydrated Salt-Pluronic Interactions: Spectroscopic Studies. The interactions, among the salt, water, and surfactants in the $\mathrm{LiCl}$ (or $\mathrm{LiNO}_{3}$ ) $\cdot x \mathrm{H}_{2} \mathrm{O}$-pluronic samples, have also been investigated by using FT-IR and micro-Raman spectroscopy. The samples were prepared by either spincoating from the solution phase over the silicon wafers or spreading over silicon directly from the LLC gel phase. The spectra were recorded under ambient laboratory conditions at RT and $22-25 \%$ relative humidity $(\mathrm{RH})$. The nitrate ion in the $\mathrm{LiNO}_{3} \cdot x \mathrm{H}_{2} \mathrm{O}$-pluronics systems interacts with the lithium ion and the corresponding peak related to the nitrate ion broadens, as observed at around $1370 \mathrm{~cm}^{-1}$, and dominates the FT-IR spectra. Figure 4 shows the FT-IR spectra of the pure pluronics (P103 and P123), $\mathrm{LiNO}_{3} \cdot x \mathrm{H}_{2} \mathrm{O}-\mathrm{P} 103-12, \mathrm{LiNO}_{3} \cdot x \mathrm{H}_{2} \mathrm{O}-\mathrm{P} 123-$ 12 , $\mathrm{LiCl} \cdot x \mathrm{H}_{2} \mathrm{O}-\mathrm{P} 103-12$, and $\mathrm{LiCl} \cdot x \mathrm{H}_{2} \mathrm{O}-\mathrm{P} 123-12$ samples.

In the transition metal nitrate salt-surfactant LLC mesophases, the doubly degenerate antisymmetric stretching mode of the nitrate ion at around $1360 \mathrm{~cm}^{-1}$ splits into two nondegenerate modes as a result of coordination. ${ }^{22}$ However, this splitting is not as strong in the $\mathrm{LiNO}_{3}$ systems, since the $\mathrm{LiNO}_{3}$ only forms ion-pair rather than $\mathrm{Li}-\mathrm{ONO}_{2}$ coordina- 


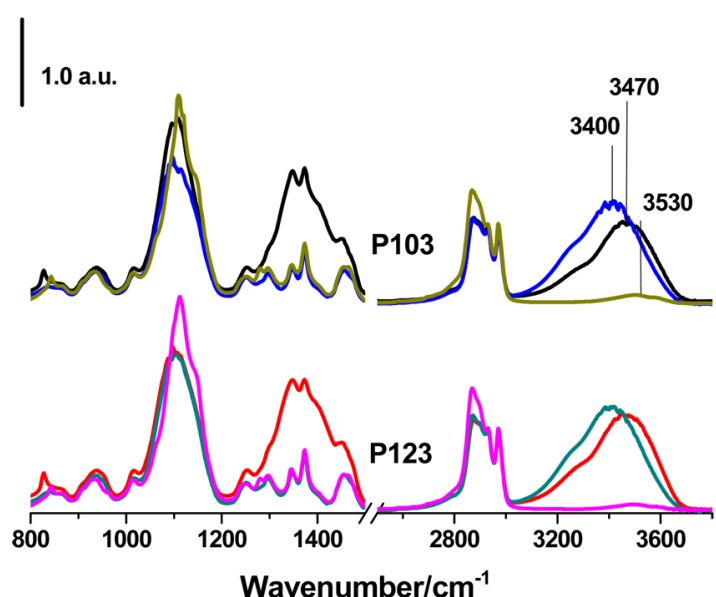

Figure 4. FT-IR spectra of (bottom) P123 (dark green), $\mathrm{LiCl} \cdot x \mathrm{H}_{2} \mathrm{O}$ P123-12 (blue), and $\mathrm{LiNO}_{3} \cdot x \mathrm{H}_{2} \mathrm{O}-\mathrm{P} 123-12$ (black) and (top) $\mathrm{P} 103$ (pink), $\mathrm{LiCl} \cdot x \mathrm{H}_{2} \mathrm{O}-\mathrm{P} 103-12$ (green), and $\mathrm{LiNO}_{3} \cdot x \mathrm{H}_{2} \mathrm{O}-\mathrm{P} 103-12$ (red).

tion. ${ }^{19,41}$ On the other hand, some changes in the pluronic region were observed, showing that the surfactant molecules also display conformational changes due to the addition of salt into the media. The $v-\mathrm{C}-\mathrm{O}$ stretching region of the surfactant shifts to lower energy in the salted systems. This demonstrates that there is a hydrogen-bonding interaction between the hydration sphere of the ions $\left(\mathrm{Li}^{+}\right.$and $\left.\mathrm{NO}_{3}{ }^{-}\right)$and the ethoxy groups of the surfactant molecules.

The $\mathrm{LiNO}_{3} \cdot x \mathrm{H}_{2} \mathrm{O}$-pluronic mesophases were also investigated using micro-Raman spectroscopy. The peaks at 1030 and $1045 \mathrm{~cm}^{-1}$ are due to the hydrated ion pairs $\left(\mathrm{Li}^{+}-\mathrm{NO}_{3}{ }^{-}\right)$ and hydrated free nitrate $\left(\mathrm{NO}_{3}{ }^{-}\right)$ions, respectively (see Figure 5). The intensity of the free nitrate ion is much stronger compared to the intensity of the ion-paired nitrate ions. Moreover, the intensity of the free nitrate ion peak increases with increasing salt concentration in the media, indicating that the majority of the nitrate and lithium ions are free ions in the media. The stretching modes of the $\mathrm{CH}_{2}$ and $\mathrm{CH}_{3}$ groups of surfactants also respond to the addition of salt into the media. Relatively sharper signals at 2868 and $2927 \mathrm{~cm}^{-1}$ get broader with the addition of salt species (see Figure 5). The intensity ratio of these two peaks $I\left(\mathrm{CH}_{2}\right) / I\left(\mathrm{CH}_{3}\right)$ decreases with increasing salt concentration in the media, indicating conforma- tional changes of the ethoxy and propoxy units of the pluronics, and it is consistent with the unit cell expansion in the mesophases with an increasing salt concentration. The change in the unit cell dimensions, phase changes, and change in the FT-IR intensities of the $\nu-\mathrm{CH}_{2}$ and $\nu-\mathrm{CH}_{3}$ stretching modes are all related to the conformational changes in the $\mathrm{EO}$ units of the pluronics in the mesophases.

The FT-IR spectra were also collected at various salts per surfactant mole ratios in order to understand the effect of anions on the phase behavior. Figure S8 displays the FT-IR spectra of different systems with an increasing salt concentration. The intensity of the $\nu-\mathrm{OH}$ band of water at around $3100-3700 \mathrm{~cm}^{-1}$ increases with an increasing salt concentration (see Figure 6 and Figure S8). This means that the salt

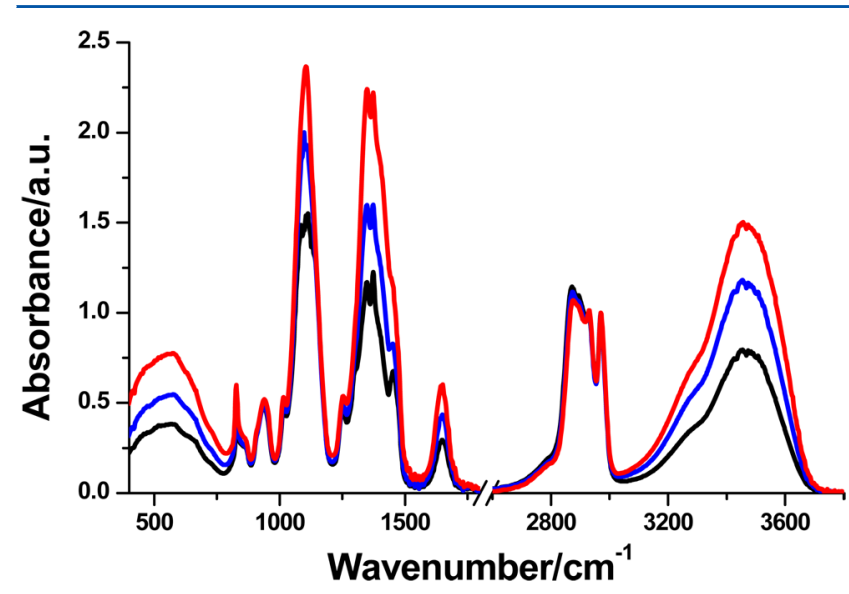

Figure 6. FTIR spectra of $\mathrm{LiNO}_{3} \cdot x \mathrm{H}_{2} \mathrm{O}-\mathrm{P} 103-n$, where $n$ is 8 (black), 12 (blue), and 15 (red).

concentration determines the amount of water kept (hydration water) in the LLC mesophase. The salt ions are hydrated in the LLC mesophase, where the excess free water evaporates. Hence, the amount of water is directly proportional with the mole ratio of the salt in the media. It is also important to notice that the amount of water kept in the mesophases is larger in the $\mathrm{LiCl}$ system compared to the $\mathrm{LiNO}_{3}$ system; compare the spectra in Figure 4. Also notice that the molten surfactants have a $\nu$-CO stretching maxima at around $1120 \mathrm{~cm}^{-1}$. This band shifts to 1104 and $1100 \mathrm{~cm}^{-1}$ in the $\mathrm{LiCl}$ and $\mathrm{LiNO}_{3}$ systems,
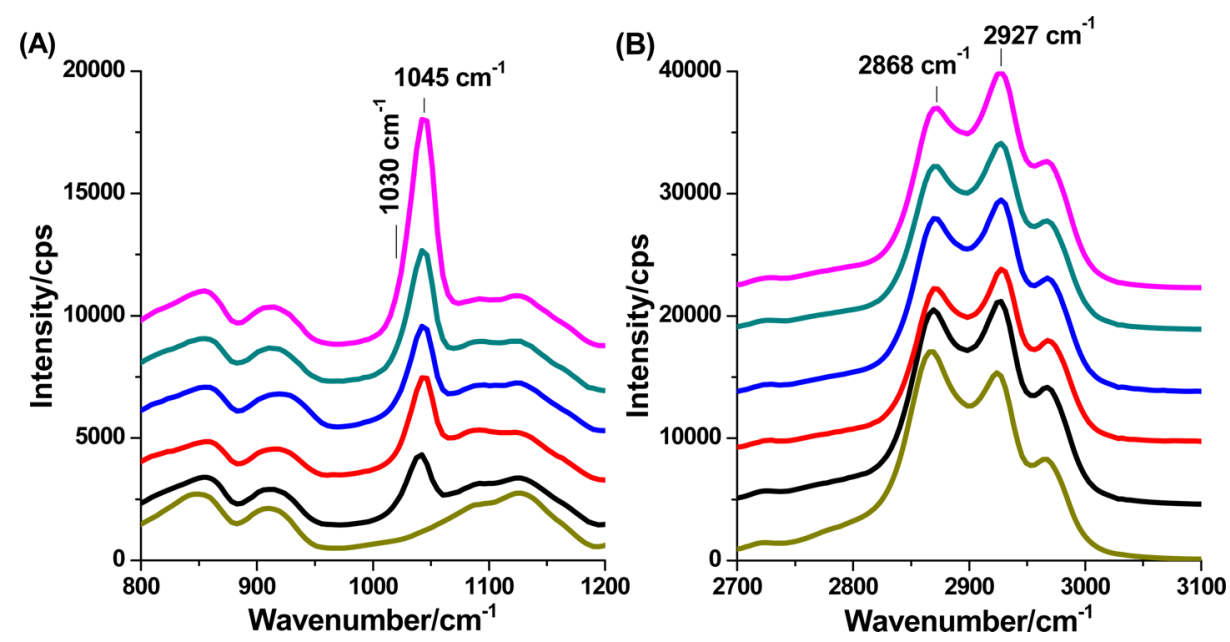

Figure 5. Micro-Raman spectra of $\mathrm{P} 123$ and the $\mathrm{LiNO}_{3} \cdot x \mathrm{H}_{2} \mathrm{O}-\mathrm{P} 123-n$, where $n$ is $6,8,10,12$, and 15 (from bottom to top). 
respectively. The amount of water in the LLC mesophase also depends on the anion as was discussed in the PXRD section. The maxima of the $\nu-\mathrm{OH}$ stretching band is at around 3400 $\mathrm{cm}^{-1}$ in the spectra of $\mathrm{LiCl} \cdot x \mathrm{H}_{2} \mathrm{O}-\mathrm{P} 123$ and $\mathrm{LiCl} \cdot x \mathrm{H}_{2} \mathrm{O}-\mathrm{P} 103$, $3470 \mathrm{~cm}^{-1}$ in the $\mathrm{LiNO}_{3}$ systems, and $3530 \mathrm{~cm}^{-1}$ in the pure surfactant spectra (Figure 4). The red-shift indicates that the interaction between the ions and water and the $\mathrm{Cl}^{-}$anions and water is stronger than that of the $\mathrm{NO}_{3}{ }^{-}$anions and water interactions.

In order to understand the role of water and the water up take of the samples, we also prepared five samples each of P103 with $10 \mathrm{LiCl}$ and $10 \mathrm{LiNO}_{3}$ with water contents of 2, 5, 10, 15, and 20 water/salt mole ratios (total 10 samples). The FTIR spectra of the samples were recorded between two silicon wafers that prevent evaporation water. The spectra were normalized using the surfactant peak at $1456 \mathrm{~cm}^{-1}$ in order to obtain a calibration curve (the water content versus absorbance at $1645 \mathrm{~cm}^{-1}$, bending mode of water) (see Figure S9). Then, the FTIR spectra of some of above samples were also recorded by spreading over a single silicon wafer, where the excess water evaporates immediately upon spreading and reaches to an optimum water content, independent of the initial water content of the samples but dependent on the salt content. The peak at $1645 \mathrm{~cm}^{-1}$ was monitored for $24 \mathrm{~h}$ to make sure the water content in the sample is the final content (Figure S10). Using these spectra and the calibration curve, we calculated the amount of water in the samples and determined that the nitrate samples keep around $1.5 \mathrm{H}_{2} \mathrm{O} / \mathrm{LiNO}_{3}$ in the $\mathrm{LiNO}_{3} \cdot 15 \mathrm{H}_{2} \mathrm{O}$ $\mathrm{P} 103-10$ and around $3.0 \mathrm{H}_{2} \mathrm{O} / \mathrm{LiCl}$ in the $\mathrm{LiCl} \cdot 30 \mathrm{H}_{2} \mathrm{O}-\mathrm{P} 103-10$ samples, no matter what the initial water content of the samples was (both $\mathrm{LiCl} \cdot x \mathrm{H}_{2} \mathrm{O}-\mathrm{P} 103-10$ and $\mathrm{LiNO}_{3} \cdot x \mathrm{H}_{2} \mathrm{O}-\mathrm{P} 103-10$, where $x$ is 2 and 15). Notice that these quantities are much lower than the solubility of these salts in pure water (the minimum water required to dissolve $1 \mathrm{~mol}$ of $\mathrm{LiNO}_{3}$ is around $7.0 \mathrm{~mol}$ of water molecules and that for $\mathrm{LiCl}$ is $4.3 \mathrm{~mol}$ of water molecules). Also note that the melting points of $\mathrm{LiNO}_{3}$ and $\mathrm{LiCl}$ are 255 and $605{ }^{\circ} \mathrm{C}$, respectively. We established in our previous studies that confining salt species in the hydrophilic domains of the LLC mesophases depresses its melting point ${ }^{11}$ and also enhances its solubility. ${ }^{43}$ Even though the solubility of the $\mathrm{LiNO}_{3}$ is lower than $\mathrm{LiCl}$ in water, the lower melting point of $\mathrm{LiNO}_{3}$ makes it require less water in a stable LLC mesophase of $\mathrm{LiNO}_{3} \cdot x \mathrm{H}_{2} \mathrm{O}-\mathrm{P} 103-n$. The above observations are also consistent with the current understanding of the Hofmeister effect, in that the $\mathrm{Cl}^{-}$ion is a water structure maker and keeps the structure of bulk water in the LLC media, where the $\mathrm{NO}_{3}{ }^{-}$ ion is a structure breaker and breaks the structure of the bulk water and diffuses into the hydrophilic-hydrophobic interface of the LLC phase with the hydration sphere and therefore cannot hold much water.

Ionic Conductivity and Thermal Properties of Lithium Salt-Pluronic Systems. The ionic conductivities of the LLC mesophases of various lithium salt-pluronic systems were also measured by using ac impedance spectroscopy. Samples were prepared with the same salt and water mole ratios $(10.0 \mathrm{~mol}$ of salt and $200.0 \mathrm{~mol}$ of water per mole of surfactant). Stainlesssteel electrodes were used with a diameter of $4 \mathrm{~mm}$, and the electrodes were a distance of $2.3 \mathrm{~mm}$ from each other. The cell constant was measured as $0.62 \mathrm{~cm}^{-1}$ by using $0.01 \mathrm{M}$ standard $\mathrm{KCl}$ solution at $\mathrm{RT}$. Conductivity was calculated by converting the measured resistances with the formula $\sigma=K R^{-1}$, where $K$ is the cell constant and $R$ is the measured resistance.
Figure S11 indicates Nyquist plots of various samples, where the imaginary part of the impedance is equal to zero at the high-frequency region. The ionic conductivities of various $\mathrm{LiCl}$. $x \mathrm{H}_{2} \mathrm{O}$-pluronics were recorded in the range between 21 and 1.9 $\mathrm{mS} / \mathrm{cm}$. The highest conductivity was obtained from the $\mathrm{LiCl}$. $x \mathrm{H}_{2} \mathrm{O}-\mathrm{P} 65$ system as $21 \mathrm{mS} / \mathrm{cm}$ (see Table 2). The observed

Table 2. Phase Behavior of $\mathrm{LiCl} \cdot \mathrm{xH}_{2} \mathrm{O}$-Pluronics and $\mathrm{LiNO}_{3} \cdot$ $x \mathrm{H}_{2} \mathrm{O}$-Pluronics Systems at RT and 22-25\% $\mathrm{RH}^{a}$

$\begin{array}{lccccc}\text { LLC phase } & \mathrm{IT}\left({ }^{\circ} \mathrm{C}\right) & \mathrm{CP}\left({ }^{\circ} \mathrm{C}\right) & \mathrm{MP}\left({ }^{\circ} \mathrm{C}\right) & R(\Omega) & \sigma(\mathrm{mS} / \mathrm{cm}) \\ \text { P65-LiCl } & 52 & 59 & 64 & 25.7 & 21.0 \\ \text { P85-LiCl } & 69 & 73 & 76 & 332.2 & 1.9 \\ \text { P103-LiCl } & 56 & 72 & 89 & 286.7 & 2.0 \\ \text { P123-LiCl } & 76 & 80 & 92 & 315.4 & 2.2 \\ \text { P103-LiNO }_{3} & 78 & 97 & 105 & 150.2 & 4.1 \\ \text { P123-LiNO }_{3} & 83 & 104 & 113 & 2790 & 0.2\end{array}$

${ }^{a} \mathrm{IT}$ is isotropization temperature, CP is cloud point, MP is melting point, $\mathrm{R}$ is resistance, and $\sigma$ is conductivity.

higher conductivity from the $\mathrm{LiCl} \cdot \mathrm{H}_{2} \mathrm{O}-\mathrm{P} 65$ system could be attributed to smaller size and segmental motion of P65. However, more detailed studies are required to elucidate the details of these phenomena.

Although all the samples were prepared with the same water to salt mole ratio, the amount of water in the mesophase stabilizes to 1.5 water molecules per $\mathrm{LiNO}_{3}$ and 3.0 water molecules per $\mathrm{LiCl}$ in the samples over time. The excess water evaporates immediately, and the samples become stable in terms of the amount of water over time (see Figure S12). According to the time-dependent FT-IR spectra of the LiCl$200 \mathrm{H}_{2} \mathrm{O}-\mathrm{P} 65-10$ sample, around $70 \%$ of water evaporates while spreading the samples over the silicon wafer and loses another $13.2 \%$ in first $5 \mathrm{~min}$, and the total amount of water decreases to $15 \%$ (corresponds to 30 water for $10 \mathrm{LiCl}$ ) at the end of $9 \mathrm{~h}$. Figure $\mathrm{S} 13$ shows the conductivities of the $\mathrm{LiCl} \cdot x \mathrm{H}_{2} \mathrm{O}-\mathrm{P} 65-n$ samples with an increasing water concentration. The ionic conductivity of the samples with 5.0, 7.5, 10.0, and 15.0 water/ salt mole ratios were recorded immediately. According to the conductivity data, the conductivity is proportional to the amount of water in the LLC mesophases. As the amount of water decreases, the resistance increases and so the conductivity decreases in the sample.

The LLC mesophases of $\mathrm{LiCl} \cdot x \mathrm{H}_{2} \mathrm{O}$-pluronics and $\mathrm{LiNO}_{3}$. $x \mathrm{H}_{2} \mathrm{O}$-pluronics were further characterized by determining the isotropization temperature (IT). The IT can be regarded as the melting point in some composition, but it can also be a hexagonal to cubic or disordered phase change in some other compositions. To fully elucidate the nature of the isotropization temperature in every composition, the phase diagram of each system needs to be constructed which require further investigations. The IT of the samples with 10 salts to surfactant mole ratio in all systems was determined by heating and cooling and was monitored using a polarized optical microscope. A small amount of sample was put on a microscope slide and sealed with a cover glass and taped in order to prevent evaporation of water from the mesophase during heating. ITs were recorded as the point where the characteristic fan texture of hexagonal mesophase disappeared, and a totally dark image was observed. ITs of the $\mathrm{LiCl}$ samples were determined to be in the range of $52-67^{\circ} \mathrm{C}$, whereas the ITs of the $\mathrm{LiNO}_{3}$ samples were between 78 and $83{ }^{\circ} \mathrm{C}$ (see Table 2). It is obvious that the $\mathrm{LiCl}$ systems have lower ITs than those of $\mathrm{LiNO}_{3}$ systems with 
the same surfactants. This is also related to Hofmeister series, where the $\mathrm{Cl}^{-}$ion has higher kosmotropic character than the $\mathrm{NO}_{3}{ }^{-}$ion. ${ }^{12-14}$ Therefore, the $\mathrm{Cl}^{-}$ion has a higher tendency to increase the hydrogen-bonding network structure of water. This leads to an increase in the hydrophobic moieties and a decrease in the ITs of the $\mathrm{LiCl}$ systems. Similar trends were also observed for the melting points and cloud points of the mesophases. The cloud point is the temperature where the solutes are not completely soluble, and their precipitation gives a cloudy appearance to the substance. ${ }^{46}$ The $\mathrm{LiNO}_{3}$ systems have cloud points higher than $95{ }^{\circ} \mathrm{C}$ and melting points higher than $100{ }^{\circ} \mathrm{C}$, which are much higher than those of the $\mathrm{LiCl}$ samples (see Table 2) and are consistent with their water uptake and the kosmotropic nature of the chloride ion.

\section{CONCLUSION}

Hydrated lithium salts $\left(\mathrm{LiCl} \cdot x \mathrm{H}_{2} \mathrm{O}\right.$ and $\left.\mathrm{LiNO}_{3} \cdot x \mathrm{H}_{2} \mathrm{O}\right)$ form stable lyotropic liquid crystalline mesophases with various pluronics (P65, P85, P103, and P123) over a very broad range of salt/surfactant mole ratio (3-30). The hydrated salt-pluronic mesophases are hexagonal and birefringent in the intermediate salt concentrations (usually between 5 and 15 salt/surfactant mole ratios) and transform to a cubic phase, followed by a disordered phase and finally to liquid phase with an increasing salt content. However, at low salt concentration, the pluronics leach out from the mesophase to form salt-rich hexagonal LLC mesophase and salt-free pure surfactant phase. The phase separation takes place up to a relatively higher salt concentration in the P65 and P85 systems that the likely reason is the stronger surfactant-surfactant interactions due to high ethylene oxide/propylene oxide ratios. However, P103 and P123 samples are stable even at lower salt contents. Therefore, increasing PPO/PEO ratio in the pluronics stabilizes the saltpluronic mesophases by enhancing attractive hydrophobic interactions in the core regions (PPO region) and reducing repulsive forces in the ethylene oxide shell regions.

Furthermore, the mesophases can be dissolved in excess water to obtain the clear solution, which can then be coated as a thin film by spin coating over any substrate. The excess water evaporates almost immediately after spin coating to $1.5 \mathrm{H}_{2} \mathrm{O}$ / $\mathrm{LiNO}_{3}$ and $3.0 \mathrm{H}_{2} \mathrm{O} / \mathrm{LiCl}$ mole ratios in the $\mathrm{LiNO}_{3}$ and $\mathrm{LiCl}$ mesophases, respectively, to form their stable LLC mesophases. The spin rate and also the amount of excess water determine the thickness of the final LLC film. The mesophases have a high ionic conductivity, as high as $21 \mathrm{mS} / \mathrm{cm}$ at $\mathrm{RT}$, and high melting points, as high as $115^{\circ} \mathrm{C}$.

\section{ASSOCIATED CONTENT}

\section{S Supporting Information}

More PXRD, FTIR, and conductivity related data. This material is available free of charge via the Internet at http://pubs.acs.org.

\section{AUTHOR INFORMATION}

\section{Corresponding Author}

*E-mail dag@fen.bilkent.edu.tr; Tel 90312 2903918; Fax 90 3122665048 (Ö.D.).

\section{Notes}

The authors declare no competing financial interest.

\section{ACKNOWLEDGMENTS}

Authors thank TÜBİTAK under the project number 112T407 for financial support. Ö.D. is a member of Science Academy, Istanbul, Turkey.

\section{ABBREVIATIONS}

LLC, lyotropic liquid crystal; LLCM, lyotropic liquid crystalline mesophase; DRH, deliquescent relative humidity; PX (P65, $\mathrm{P} 85, \mathrm{P} 103, \mathrm{P} 123$ ), pluronics (triblock copolymer, $\mathrm{H}$ $\left.\left(\mathrm{OCH}_{2} \mathrm{CH}_{2}\right)_{n}\left(\mathrm{OCH}\left(\mathrm{CH}_{3}\right) \mathrm{CH}_{2}\right)_{m}\left(\mathrm{OCH}_{2} \mathrm{CH}_{2}\right)_{n} \mathrm{OH}\right)$.

\section{REFERENCES}

(1) Ren, Y.; Armstrong, R.; Jiao, F.; Bruce, P. G. Influence of size on the rate of mesoporous electrodes for lithium batteries. J. Am. Chem. Soc. 2010, 132, 996-1004.

(2) Kim, M. G.; Cho, J. Reversible and high-capacity nanostructured electrode materials for Li-ion batteries. Adv. Funct. Mater. 2009, 19 (10), 1497-1514.

(3) Poizot, P.; Laruelle, S.; Grugeon, S.; Dupont, L.; Tarascon, J.-M. Nano-sized transition metal oxides as negative-electrode materials for lithium-ion batteries. Nature 2000, 407, 496-499.

(4) Choi, N.-S.; Chen, Z.; Freunberger, S. A.; Ji, X.; Sun, Y.-K.; Amine, K.; Yushin, G.; Nazar, L. F.; Chao, J.; Bruce, P. G. Challenges facing lithium batteries and electrical double-layer capacitors. Angew. Chem., Int. Ed. 2012, 51, 9994-10024.

(5) Attard, G. S.; Glyde, J. C.; Göltner, C. G. Liquid-crystalline phases as templates for the synthesis of mesoporous silica. Nature 1995, 378, 366-368.

(6) Braun, P. V.; Osenar, P.; Stupp, S. I. Semiconducting superlattices template by molecular assemblies. Nature 1996, 380, 325-328.

(7) Attard, G. S.; Bartlett, P. N.; Coleman, N. R. B.; Elliott, J. M.; Owen, J. R. Lyotropic liquid crystalline properties of nonionic surfactant $/ \mathrm{H}_{2} \mathrm{O} /$ hexachloroplatinic acid ternary mixtures used for the production of nanostructured platinum. Langmuir 1998, 14, 73407342.

(8) Yamauchi, Y.; Momma, T.; Yokoshima, T.; Kuroda, K.; Osaka, T. Highly ordered mesostructured $\mathrm{Ni}$ nanoparticles prepared from lyotropic liquid crystals by electroless deposition: the effect of reducing agents on the ordering of mesostructure. J. Mater. Chem. 2005, 15, 1987-1994.

(9) Türker, Y.; Dag, Ö. Synthesis of mesostructured metal sulfide films using $\left[\mathrm{M}\left(\mathrm{H}_{2} \mathrm{O}\right)_{\mathrm{n}}\right]\left(\mathrm{NO}_{3}\right)_{2}-\mathrm{P} 85(\mathrm{M}=\mathrm{Cd}(\mathrm{II})$ and $\mathrm{Zn}(\mathrm{II}))$ liquid crystalline mesophases. J. Mater. Chem. 2008, 18, 3467-3473.

(10) Mitchell, D. J.; Tiddy, G. J. T.; Waring, L.; Bostock, T.; McDonald, M. P. Phase behavior of polyoxyethylene surfactants with water. Mesophase structures and partial miscibility (cloud points). J. Chem. Soc., Faraday Trans. 1 1983, 79, 975-1000.

(11) Dong, R.; Hao, J. Complex fluids of poly(oxyethylene) monoalkyl ether nonionic surfactants. Chem. Rev. 2010, 110, 49785022.

(12) Alexandridis, P.; Zhou, D.; Khan, A. Lyotropic liquid crystallinity in amphiphilic block copolymers: temperature effects on phase behavior and structure for poly(ethylene oxide)-b-poly(propylene oxide)-b-poly(ethylene oxide) copolymers of different composition. Langmuir 1996, 12, 2690-2700.

(13) Weckström, K.; Zulauf, M. Lower sonsolute boundaries of a poly(oxyethylene) surfactant in aqueous solution of monovalent salts. J. Chem. Soc., Faraday Trans. I 1985, 81, 2947-2958.

(14) Zheng, L.-Q.; Minamikawa, H.; Harada, K.; Inoue, T.; Chernik, G. G. Effect of inorganic salts on the phase behavior of an aqueous mixture of heptaethylene glycol dodecyl ether. Langmuir 2003, 19, 10487-10494.

(15) Inoue, T.; Yokoyama, Y.; Zheng, L.-Q. Hofmeister anion effect on aqueous phase behavior of heptaethylene glycol dodecyl ether. $J$. Colloid Interface Sci. 2004, 274, 349-353.

(16) Ganguly, R.; Aswal, V. K.; Hassan, P. A.; Gopalakrishnan, I. K.; Yakhmi, J. V. Sodium chloride and ethanol induced shere to rod 
transition of triblock copolymer micelles. J. Phys. Chem. B 2005, 109, $5653-5658$

(17) Greaves, T. L.; Drummond, C. J. Ionic liquids as amphiphile self-assembly media. Chem. Soc. Rev. 2008, 37, 1709-1726.

(18) Hollamby, M. J.; Trickett, K.; Mohamed, A.; Eastoe, J.; Rogers, S. E.; Heenan, K. Surfactant aggregation in $\mathrm{CO}_{2} /$ heptane solvent mixtures. Langmuir 2009, 25, 12909-12913.

(19) Seguin, C.; Eastoe, J.; Heenan, R. K.; Grillo, I. Controlling aggregation of nonionic surfactants using mixed glycol media. Langmuir 2007, 23, 4199-4202.

(20) Alexandridis, P.; Olsson, U.; Lindman, B. A record nine different phases (four cubic, two hexagonal, and one lamellar lyotropic liquid crystalline and two micellar solutions) in a ternary isothermal system of an amphiphilic block copolymer and selective solvents (water and oil). Langmuir 1998, 14, 2627-2638.

(21) Soni, S. S.; Brotons, G.; Bellour, M.; Narayanan, T.; Gibaud, A. Quantitative SAXS analysis of the P123/water/ethanol ternary phase diagram. J. Phys. Chem. B 2006, 110, 15157-15165.

(22) Çelik, Ö.; Dag, Ö. A new lyotropic liquid crystalline system: Oligo(ethylene oxide) surfactants with $\left[\mathrm{M}\left(\mathrm{H}_{2} \mathrm{O}\right)_{\mathrm{n}}\right] \mathrm{X}_{\mathrm{m}}$ transition metal complexes. Angew. Chem., Int. Ed. 2001, 40, 3800-3803.

(23) Albayrak, C.; Özkan, N.; Dag, Ö. Origin of lyotropic liquid crystalline mesophase formation and liquid crystalline to mesostructured solid transformation in the metal nitrate salt-surfactant systems. Langmuir 2011, 27, 870-873.

(24) Karakaya, C.; Türker, Y.; Dag, Ö. Molten salt-assisted selfassembly (MASA)-synthesis of mesoporous metal titanate-titania, metal sulfide-titania, and metal selenide-titania thin films. Adv. Funct. Mater. 2013, 23, 4002-4010.

(25) Dag, Ö.; Alayoglu, S.; Uysal, I. Effects of ions on the liquid crystalline mesophases of transition metal salt:surfactant $\left(\mathrm{C}_{\mathrm{n}} \mathrm{EO}_{\mathrm{m}}\right) . J$. Phys. Chem. B 2004, 108, 8439-8446.

(26) Tarascon, J.-M.; Armand, M. Issues and challenges facing rechargeable lithium batteries. Nature 2001, 414, 359-367.

(27) Song, J. Y.; Wang, Y. Y.; Wan, C. C. Review of gel-type polymer electrolytes for lithium ion batteries. J. Power Sources 1999, 77, 183197.

(28) Kato, T. Self-assembly of phase-segregated liquid crystal structures. Science 2002, 295, 2414-2418.

(29) Ohtake, T.; Takamitsu, Y.; Ito-Akito, K.; Kanic, K.; Yoshizawa, M.; Mukai, T.; Ohno, H.; Kato, T. Liquid-crystalline ion conductive materials: self-organization of mesogenic dimers containing oxyethylene moieties complexed metal salts. Macromolecules 2000, 33, 8109-8111.

(30) Judeinstein, P.; Roussel, F. Ionic conductivity of lithium salt/ oligo(ethylene oxide)-based liquid crystal mixtures: the effect of molecular architecture on the conduction process. Adv. Mater. 2005, 17, 723-727.

(31) Shimura, H.; Yoshio, M.; Hoshino, K.; Mukai, T.; Ohno, H.; Kato, T. Noncovelent approach to one-dimensional ion conductors: enhancement of ionic conductivities in nanostructured columnar liquid crystals. J. Am. Chem. Soc. 2008, 130, 1759-1765.

(32) Kerr, R. L.; Miller, S. A.; Shoemaker, R. K.; Elliott, B. J.; Gin, D. $\mathrm{L}$. New type of $\mathrm{Li}$ ion conductor with $3 \mathrm{D}$ interconnected nanopores via polymerization of a liquid organic electrolyte-filled lyotropic liquid crystal assembly. J. Am. Chem. Soc. 2009, 131, 15972-15973.

(33) Soni, S. S.; Fadadu, K. B.; Gibaud, A. Ionic conductivity through thermoresponsive polymer gel: ordering matter. Langmuir 2012, 28, $751-756$.

(34) Jiao, F.; Shaju, K. M.; Bruce, P. G. Synthesis of nanowire and mesoporous low-temperature $\mathrm{LiCoO}_{2}$ by a post-templating reaction. Angew. Chem., Int. Ed. 2005, 44, 6550-6553.

(35) Shen, L.; Yuan, C.; Luo, H.; Zhang, X.; Chen, L.; Li, H. Novel template-free solvothermal synthesis of mesoporous $\mathrm{Li}_{4} \mathrm{Ti}_{5} \mathrm{O}_{12}-\mathrm{C}$ microspheres for high power lithium ion batteries. J. Mater. Chem. 2011, 21, 14414-14416.

(36) Wang, J.; Zhou, Y.; Hu, Y.; O’Hayre, R.; Shao, Z. Facile synthesis of nanocrystalline $\mathrm{TiO}_{2}$ mesoporous microspheres for lithium-ion batteries. J. Phys. Chem. C 2011, 115, 2529-2536.
(37) Luo, J.-Y.; Wang, Y.-G.; Xia, Y.-Y. Ordered mesoporous spinel $\mathrm{LiMn}_{2} \mathrm{O}_{4}$ by a soft-chemical process as a cathode material for lithiumion batteries. Chem. Mater. 2007, 19, 4791-4795.

(38) Kang, E.; Jung, Y. S.; Kim, G.-H.; Chun, J.; Wiesner, U.; Dillon, A. C.; Kim, J. K.; Lee, J. Highly improved rate capability for a lithiumion battery nano- $\mathrm{Li}_{4} \mathrm{Ti}_{5} \mathrm{O}_{12}$ negative electrode via carbon-coated mesoporous uniform pores with a simple self-assembly method. $A d v$. Funct. Mater. 2011, 21, 4349-4357.

(39) Haetge, J.; Hartman, P.; Brezensinski, K.; Janek, J.; Brezensinski, $\mathrm{T}$. Ordered large-pore mesoporous $\mathrm{Li}_{4} \mathrm{Ti}_{5} \mathrm{O}_{12}$ spinel thin film electrodes for application in high rate rechargeable lithium batteries and hybrid supercapacitors: relation-ships among charge storage, electrical conductivity and nanoscale structure. Chem. Mater. 2011, 23, 438493.

(40) Yu, L.; Wu, H. B.; Lou, X. W. Mesoporous $\mathrm{Li}_{4} \mathrm{Ti}_{5} \mathrm{O}_{12}$ hollow spheres with enhanced lithium storage capability. Adv. Mater. 2013, 25, 2296-2300.

(41) Law, C.-H.; Pathirana, S. C.; Li, X.; Anderson, A. Y.; Barnes, P. R. F.; Listorli, A.; Chaddar, T. H.; O’Regan, B. C. Water-based electrolytes for dye-sensitized solar cells. Adv. Mater. 2010, 22, 45054509.

(42) Hallinan, D. T.; Balsara, N. P., Jr. Polymer electrolytes. Annu. Rev. Mater. Res. 2013, 43, 503-525.

(43) Albayrak, C.; Cihaner, A.; Dag, Ö. A new, highly conductive, lithium salt/nonionic surfactant, lyotropic liquid-crystalline mesophase and its application. Chem.-Eur. J. 2012, 18, 4190-4193.

(44) Demirörs, A. F.; Eser, B. E.; Dag, Ö. Liquid crystalline mesophases of pluronics (L64, P65, and P123) and transition metal nitrate salts $\left(\left[\mathrm{M}\left(\mathrm{H}_{2} \mathrm{O}\right)_{6}\right]\left(\mathrm{NO}_{3}\right)_{2}\right)$. Langmuir 2005, 21, 4156-4162.

(45) Park, M. J.; Char, K. Two gel states of a PEO-PPO-PEO triblock copolymer formed by different mechanism. Macromol. Rapid Commun. 2002, 23, 688-692.

(46) Corti, M.; Minero, C.; Degiorgio, V. Cloud point transition in nonionic micellar solutions. J. Phys. Chem. 1984, 88, 309-317. 